\title{
Analysis of macro-and microplastics in the water, soil/sediment in riverine, riverbanks and irrigated farms in Arusha Tanzania
}

Mercy Nasimiyu Kundu ( $\square$ Kundum@nm-aist.ac.tz)

Nelson Mandela African Institute of Science and Technology https://orcid.org/0000-0002-0145-6275 Hans Komakech

Nelson Mandela African Institute of Science and Technology

George Lugomela

Ministry of water

\section{Research Article}

Keywords: solid waste management, irrigation farms, Africa, macro-and microplastics

Posted Date: April 30th, 2021

DOl: https://doi.org/10.21203/rs.3.rs-456459/v1

License: (c) This work is licensed under a Creative Commons Attribution 4.0 International License.

Read Full License 


\section{Abstract}

Microplastics and macroplastics have been reported in different urban rivers and agricultural soil across the globe. However, the interlink between them has not been previously assessed therefore, the present study evaluated the relationship between macro-and microplastics in the water columns and sediments in riverine, riverbanks, and soils from irrigated farms in Arusha, Tanzania. Detached pieces from macroplastics and suspected particles of microplastics from the samples were analyzed using the total attenuated reflectance - Fourier transform Infrared spectroscopy, where statistical analysis showed that the number of microplastics in the sediments was higher than in the water columns and that in irrigated farms than in the riverine by a magnitude of 4 . Besides, the numbers of microplastics and macroplastics in the irrigation farms were exponentially-related while the macroplastics from the riverbanks had an inverse relationship with the rivers' profile elevation. Polyethylene was the dominating macroplastic in the riverbanks and irrigated farms with a $100 \%$ frequency of occurrence while polystyrene was abundant in all samples of microplastics. However, the irrigated farms adjacent to canals had a greater number of microplastics and macroplastics. In generally, the findings showed a similar trend of plastic distribution in urban rivers and irrigated farms, suggesting an interaction between them.

\section{Introduction}

The indiscriminate disposal of plastic debris and inappropriate solid waste management in urban areas foster their accumulation and contamination of the environment. Generally, plastic products are characterized by a long life cycle, hence long persistence in the environment once disposed of (Merga et al., 2020). Coupled with poor management, the persistence of plastics in various environmental compartments poses adverse effects on aquatic organisms, soil quality, human health, and productivity of plants in farms (Merga et al., 2020; Lahens et al., 2018). Plastic debris can either be classified as macroplastics (diameter $>5 \mathrm{~mm}$ ) or microplastics (diameter $<5 \mathrm{~mm}$ ) (Thompson et al., 2009). Additionally, they can be classified based on their source/origin as either primary or secondary (Angnunavuri et al., 2020). Their main sources of introduction into the environment include wastewater treatment plants, landfills, fishing, irrigation, river laundering, and the use of greenhouses in farms (Mehdinia et al., 2020; Mintenig et al., 2020).

Several studies have assessed the extent and effect of macro-and microplastics pollution in riverine systems and the surrounding environment; Kataoka et al., (2019) showed that there is a significant correlation between the concentration of microplastics and the population density of an area and the concentration of macro-and microplastics in rivers are related to behaviors of the local people and waste management practices (Rafique et al., 2020). Moreover, the longitudinal distribution of microplastics in water columns is often associated with the land use and hydrodynamics of an area (Chen et al., 2020), while the quantity of macroplastics loading into river systems is related to the concentration of microplastics in a riverine environment (Lahens et al., 2018), and the number of microplastics often tends to increase downstream (Mani et al., 2015). 
Preliminary studies on soils have reported a large number of macro-and microplastics on conventional agricultural land where they are at times applied as conditioners (Piehl et al., 2018), microplastics were reported to alter water cycles in the soil horizon (de Souza Machado et al., 2018), while others migrate into deep soil layers Rillig et al., (2017) or influence the shape, size, and surface properties of particles resulting from "ecocorona" in the soil (Galloway et al., 2017). These studies have been conducted on agricultural farms where plastic materials have been applied purposely as addictive, plasticizers, on land sludge applications, or at lab scale.

However, no study has demonstrated the interaction between the concentration of macro-and microplastics in urban rivers and the irrigation farms, Although, the interaction between the macro-and microplastics in urban rivers and irrigated farms is vital to provide a broad knowledge on the level of pollution in the agricultural environment (Walton, et al., 2017). The present study was an attempt to evaluate the interaction between macro-and microplastics in the river systems of water columns, sediments, and macro-and microplastics of the river system and the those found in soils of irrigated farms situated in Arusha, Tanzania which is characterized by informal settlement, poor sanitation, and poor solid waste management, leading to a high level of plastic pollution in rivers (Komakech \& de Bont, 2018).

The scope of the study was to understand the interaction between the macro-and microplastics from the urban river and the dependent farmer-led irrigation farms relying on urban rivers for irrigation with specific objectives been : i) to assess the diversity and quantity of macroplastics in the riverbanks and microplastic from the water column and the sediment, ii) to assess and quantify the diversity of microplastics and macroplastics in the dependent irrigated farms, and iii) to evaluate the relationship between the plastic debris from urban rivers and irrigation farms. The results provide an insight into the interlink between the types of macro-and microplastics from urban rivers and agricultural farms relying upon irrigation purposes.

\section{Materials And Methods \\ 2.1 Study area}

The study was conducted in November 2020 on River Themi originating from Mount Meru; constituting of three major tributaries: Burka, Naura, and Kijenge Rivers. Flowing from the mountain's slope, the river passes through Arusha City extending downwards to Bwawani area where the water is used for domestic, smallholder irrigation and for livestock purposes shown in Fig. 1. Climatically, the area is a semi-arid region, characterized by bimodal rainfall (Kijazi \& Reason, 2009), with long rains from March to June, and short rains from October to December. While the mean total annual rainfall ranges from 500 to 1200 $\mathrm{mm}$ per year with a mean value of about $842 \mathrm{~mm}$ per year (Chacha et al., 2018). Its rainfall systems have been classified with a high rainfall variability. In addition, the geological material is composed of superficial deposits from alluvium and weathered soil from the volcanic materials (Nanyaro et al., 1984). 


\subsection{Sample collection}

\subsubsection{Water and sediment samples}

A tape measure was used to measure $30 \mathrm{~m}$ long at the selected location on the riverbanks where grab water samples were taken at 3 locations using a metallic jar within a depth of $0-5 \mathrm{~cm}$ to make a composite sample of $100 \mathrm{~L}$. Concurrently, each grabbed sample was filtered through stacked stainlesssteel sieves of 5 and $0.05 \mathrm{~mm}$ to remove the large debris and retain the residue on the respective sieves, while the residues retained on the $0.05 \mathrm{~mm}$ were transferred into a glass bottle for further processing after preservation with ethanol to prevent biodegradation. Similarly, within the same marked section, utilizing the similar procedure for water; sediments were scoped from the riverbed at depth of $0-5 \mathrm{~cm}$ and stored in aluminum trays. Cumulatively, 20 samples were collected from water column and sediments of River Themi and its tributaries before transported to the laboratory for extraction of microplastics.

\subsubsection{Soil samples}

The soil sample was extracted in $30 \mathrm{~cm}$ depth layer using a handheld hoe at each point, before exhuming approximately $2 \mathrm{kgs}$ of the mixed soil sample from 3 randomly selected points to make one sample composite site described by (Thomas et al., 2020). For each farm, three composite soil samples were collected from the 2 corners and middle of the farms. In total, 9 smallholder-dependent irrigations and an agricultural farm relying on rainfall were identified for sampling. Altogether 30 composite soil samples were collected, carefully kept in aluminum trays and transported to the laboratory for further processes.

\subsubsection{Collection of macroplastics}

Macroplastics were collected from each farm and riverbank where samples for microplastics were sampled. In general, at the riverbank they were hand-picked from both sides of $30 \mathrm{~m}$ long while in the irrigated farms; samples were collected within 50 by $30 \mathrm{~m}$ rectangular areas to enable uniformity of the sampled field. After manually handpicking of all visible known plastics debris/ materials within sites, the materials were classified based on its types and counted separately before remerged for weighing using a standardized spring balance. Then, 30 detached pieces of different materials from the collected samples were analyzed using the total attenuated reflectance - Fourier transform Infrared (ATR-FTIR) spectroscopy to identify the type of polymers.

\subsection{Water quality, velocity, and river profile}

In-situ water quality parameters like dissolved oxygen (DO), electrical conductivity (EC), total dissolved solids (TDS), temperature, and $\mathrm{pH}$ were determined using a HANNA Multiparameter analyzer and $\mathrm{pH}$ meter respectively. While, the water velocity within the river columns was determined using a simple float method as described by Dobriyal et al., (2017) and the river profiles were estimated in QGIS software (Version 3.6) using the digital elevation models (DEM) images downloaded from USGS Earth explores (https://earthexplorer.usgs.gov/) and the open street maps.

\subsection{Samples Preparation}


In the laboratory, sediments and residues from water samples were dried in the oven at $55^{\circ} \mathrm{C}$ for 48 hours to drain water content before being transferred into $1 \mathrm{~L}$ glass beakers. Followed by thoroughly mixing each soil sample in the glass bowel to attain a homogeneous mixture before scoping $500 \mathrm{~g}$ for analysis of microplastics. The dried homogeneous soil was sieved through 2, 1, 0.2, $0.05 \mathrm{~mm}$ stainless sieves using a mechanical shaker for 10 minutes at 75 revolutions per second. Then, the soil retained on each sieve was carefully transferred into a glass beaker, sieves thoroughly rinsed with distilled water to ensure that all materials were recovered for further preparation as described in Sect. 2.5.

\subsection{Wet peroxide Oxidation and density separation}

Weighed dried samples of sediments, residues from water, and the sieved soil samples were subjected to wet peroxide oxidation (WPO) and density separation for the extraction of microplastics. About $100 \mathrm{ml}$ of $0.05 \mathrm{M} \mathrm{Fe}$ (II) and $200 \mathrm{ml}$ of $30 \%$ hydrogen peroxide were added into each sample as a catalyst and a digester respectively to remove organic matters (Masura et al., 2015). The prepared solutions were allowed to digest in the fume hood covered with aluminum foil for 5 days until no foam and organic matter were visible before the density separation process proceeded. Then, Sodium tungstate dehydrates $\left(\mathrm{Na}_{2} \mathrm{WO}_{4} \cdot 2 \mathrm{H}_{2} \mathrm{O}\right)$ a density separator was added into the samples and thoroughly mixed with a metallic rod to ensure that the solution interacted with all materials for proper separation (Frias et al., 2018). Where the mixed solution was allowed to settle for 24 hours in the fume hood while covered with aluminum foil, hence the supernatant was decanted and filtered through $0.45 \mu \mathrm{m} \mathrm{GF} / F, 47 \mathrm{~mm} \varnothing$, Whatman membranes to retain the desired debris, whereas the solutes retained on membranes were stored in pre-labeled Petri dishes and refrigerated for further analysis.

\subsection{Identification and categorization of microplastics}

The dissecting microscope of magnification 40X was used in visualizing the residue on the Whatman membranes to enumerate and categorize the microplastics. The enumerated microplastics were grouped depending on their sizes and types/morphology (fibers, films, fragments, and microbeads). To differentiate between microplastics and the organic matter persistent in the samples, the criteria described by Dris et al., (2015) was used. Briefly, fibers of equally thick structures were counted directly while those with entirely straight were not considered and those with no cellular or organic structures visible, transparent materials, and green fibers were examined at higher magnification power because the color is widespread among the natural materials. Once the identification was done, a hot needle test was performed for confirmation of the identified microplastics, and magnification was increased to visualize the smaller microplastics.

\subsection{Precautions for quality assurance}

During all stages of sample collection, pre-treatment, and analysis, precautions were taken to minimize the cross-contamination of samples. These precautionary they included filtering of distilled water with 0.01 um sieve for rinsing equipment and preparing of reagents, wearing of $100 \%$ cotton lab coats by all people working on samples, using glassware instead of plastics whenever possible, covering samples with aluminum foils to prevent contamination from the air, and cleaning of all used materials and 
laboratory (bench, fume hood) surfaces. In addition, procedural blank samples (3) of distilled water and crushed igneous rocks were analyzed following the same procedures used for sample preparation to confirm the cross-contamination. Consequently, the microplastics detected in the blank samples were insignificant implying minimum cross-contamination of the sample.

\subsection{Identification of polymers}

The chemical composition of the suspected materials from the samples was identified non-destructively by ATR-FTIR spectroscopy of the Bruker model at the University of Dar-salaam in Tanzania. The ATR-FTIR is a standard analytical technique for identifying the chemical composition of samples $>0.5 \mathrm{~mm}$ in size Mohamed et al., (2017) where scan was run at a resolution of $2 \mathrm{~cm}^{-1}$ between 4000 and $400 \mathrm{~cm}^{-1}$ on a Scimitar series 1000 ATR-FTIR spectroscope (Varian, Agilent Technologies Inc., USA) as described by Mohamed et al.,(2017). However, the scanned spectrums were used to identify polymer performed by comparing the measured spectra with the reference spectra library. A reference database and free software developed by Aalborg University, Denmark and Alfred Wegener Institute, Germany (SiMPle; https://simple-plastics.eu/index.html) was used for comparison. All suspected pieces from the water columns and sediments were analyzed while for irrigated farms $50 \%$ of the soil samples from each farm was analyzed based on its form. From the submitted particles, $76 \%$ of the items were confirmed as plastics. However, the method is limited in sense that it cannot detected particles with less than $0.5 \mathrm{~mm}$ diameter (Biginagwa et al., 2016).

\subsection{Statistical analysis}

Descriptive statistical analyses including the calculation of mean, standard deviation and trend lines were performed in Microsoft Excel (2010), Origin Pro (2016) was used for a graphical representation and spatial distribution maps were prepared using ArcGIS (Version 10.3).

\section{Results And Discussion}

\subsection{Spatial distribution of microplastics in the rivers}

\subsubsection{Morphology of microplastics}

A significant amount of microplastics were enumerated from all the sampled locations in the water column and sediments of River Themi and its tributaries, whereas fibers were the predominant type of morphology from both the water samples and sediments as observed in the dissecting microscope (Fig. 2a and d). Fiber typology ranged from 40 to $72 \%$ (8-78 of the total items), with the highest value detected in the water column at the first irrigation intake on River Themi, their high presences in water might be resulting from the agricultural activities carried out in the mountains sides, the indiscriminately disposal of solid waste in the area, and the heavy discharge of industrial wastewater from stabilization ponds of Arusha city. The abundance of fibers in the water samples coincides with the findings of Jiang et al.,(2019) for some rivers in the Tibetans Plateau where fibers ranged from 60 to $90 \%$ who linked the 
presence of microplastics to residential activities as the area was based in industry free and no fishing activities conducted. subsequently, fragments were the second in dominance in most of the collected samples depicting similar trend with other studies conducted in rivers (Chen et al., 2020), fragments have been described as the secondary sources associated the photo-degradation and mechanical actions of primary sources of solid and domestic wastewater (Jiang et al., 2019 Kataoka et al., 2019). Microbeads were not observed in the water columns in the present study except at one location at Naura tributary and a handful were found in the sediments, their absences in water column would be attribute to it high density and the surface area enabling its sinking in sediment. The absences of microbeads have been reported in other finding for instance River Saigon in Vietnam (Lahens et al., 2018).

\subsubsection{Quantity of microplastics}

The number of microplastics established at each location from sediments was more than those quantified in the water columns as shown in Fig. $2 \mathrm{a}$ and $\mathrm{d}$. The density and shape of microplastics could have influenced their transportation rates, deposition, and retention in the sediments (Horton \& Dixon, 2018). The concentration of microplastics in the water column could be attributed to its low density compared to water, facilitating buoyancy and floating on water. Similarly, the high number of microplastics in sediments compared to the water columns could be the effect of their high density relative to water and biofouling where the debris sinks and are deposited in sediments (Lagarde et al., 2016). The total number of microplastics established in the present study is consistent with other studies which have also reported $0.2-0.6$ items $\mathrm{L}^{-1}$ in water and $31.1-256.3$ items $\mathrm{kg}^{-1}$ in sediments respectively (Zhang et al., 2020, Dai et al., 2018). Their minor differences in the number of the items quantified from both studies, might be resulting from the differences in the method used in collecting the samples, deviations in the threshold of the size of microplastics analyzed and probability of those areas having more microplastics disposed in the area than in this study, though later is not certain as no proof provided.

The number of microplastics found in water and sediments samples collected downstream of River Themi was higher than those collected upstream except for the Kijenge tributary (Fig. 2a, d), where the high number of microplastics downstream may be attributed to both natural and anthropogenic characteristics of the river (Liro et al., 2020). In case of the river profile, morphology of the riverbed, and riparian vegetation are among the top natural factors controlling the amount and spatial distribution of plastic debris in a river system (van Emmerik et al., 2019). The higher number of microplastics downstream of River Themi is likely originating from wastewater stabilization ponds and indiscriminately-disposed plastics in the urban slums upstream, since River Themi receives treated wastewater effluents of the overloaded wastewater treatment plant (WWTP) located within Arusha. These results concur with the studies conducted by Browne et al., (2011) and McCormick et al., (2016) where a substantial amount of microplastics originating from WWTPs also contributed significantly to plastic debris loading in rivers. 
The Kijenge upstream tributary where the samples were collected is located within Arusha city and near residential houses and pedestrian footpaths. At the same site, its water velocity was very low $\left(0.43 \mathrm{~m} / \mathrm{s}^{2}\right)$, thus contributing to high retention of plastic debris retention in the water and sediment. Generally, the high number of microplastics at the first irrigation intake (canal 1) might have resulted from the combination of the river and the improvised traditional method adopted by farmers to reduce water velocity to increase the amount of water for diversion. Although accuracy was enhanced with the use of a hot needle for confirmation and a second observer, it is important to acknowledge that the number of microplastics could be subject to underestimation or overestimation due to visualization using the dissecting microscope

This study found that there is a direct relationship between the number of microplastics in the sediments and water columns $\mathrm{R}^{2}>0.3$ (Fig. $2 \mathrm{~b}$ ), inferring an increase of microplastics in the water columns may cause a subsequent increase in the number of microplastics settling in sediments. However, their relationship was not significant, therefore, other factors within the river systems could also be contributing to the retention of microplastics in the sediments. As a matter of fact, water velocity was established to have more influence on the concentration of microplastics in the sediments than in the water column (Fig. 2C), probably because low velocity increases the rate of deposition of microplastics in sediments.

In the river systems, the most frequently detected type of polymer in the water column in all the sampled locations was polystyrene $100 \%$ occurrence followed by polyethylene (PE) which was detected with $90 \%$ frequency, while in the sediments PE had a dominance of $100 \%$. The finding in this study can be correlated with the density of the materials since PS has lower density than water enabling it to float enhancing its frequency of $100 \%$ compared to PE which has high density than water column (Frias et al., 2018).

\subsection{Spatial distribution of macroplastics in the river banks 3.2.1 Distribution of macroplastics in terms of quantity}

The distribution of collected macroplastics from the river banks varied considerably (Fig. 3), with the highest weight of macroplastics were collected at Themi downstream with a total of $15 \mathrm{~kg}$ while the least quantity of $5.1 \mathrm{~kg}$ was established at Kijenge upstream. This disparity could be attributed to natural and anthropogenic activities carried at the location (Liro et al., 2020). At Themi downstream, the site is geographically located in the lower sites of the inhabitants of the city with minimal human activities conducted. In addition, the location had outcrop rocks, a gentle slope, and scattered human settlement within the vicinity; these high number of materials found here are probably deposited from the debris brought in from the city during the heavy rainfall and flooding and with aid of it gentle slope necessitating their deposition. The outcropped rocks might have place a great part too in the retention of macroplastics at the site, as during collection a huge were found trapped with rocks. Although Kijenge upstream was near a road and close to homesteads, the area has a steep slope and a narrow riverbank 
width which could have contributed to transportation of disposed-of materials downstream, thus lowering the deposited debris.

The present study also evaluated the relationship between the number of macroplastics deposited along the riverbanks and the elevations (above mean sea level) of the area as shown in Fig. 3a. The total number of macroplastics evaluated at each location was inversely proportional to the mean elevation, presumable, the total number collected in the downstream of the River tributaries were higher than those collected in the upstream, denoting deposition of more macroplastics in the lower altitudes compared to the lower one. The representation has not been compared in other studies, however, hydrological reasoning, the finding in this study in rational that more plastics are deposited in areas with gentle slopes (low river profile elevation).

\subsubsection{Type of macroplastics from the river banks}

The total number of macroplastics at each location was categorized based on their types, Fig. 3b shows the number of items per category. Where Beverage bottles of Polyethylene terephthalate (PET) type were the dominant type of macroplastics from each location except for Burka upstream which was dominated with PE materials of the low-density polyethylene (LDPE) type this could be because at the site there is sub-surface irrigation for plants and trees which could have attributed to the present results as the activities uses LDPE in mulching seedling and used as carrier and storage facilities for plants. The dominance of PET material is not surprising as utilization of plastic bottles beverages is evidenced in the shops within the area yet no management practices have been adopted for their regulations. The dominance of PET macroplastics materials were also found in River Saigon in Vietnam (Lahens et al., 2018). These consistencies of macroplastic of PET dominance in the riverine and riverbank is alarming requiring for proper management of the same to minimize their presence in the environment.

\subsection{Distribution of microplastics in the irrigated farms}

\subsubsection{Quantity of microplastics based on size}

The quantity of microplastics particles retained on the $2,1,0.2$, and $0.05 \mathrm{~mm}$ sieve ranged from 15 to 19 , 20 to 25,25 to 30 , and 30 to $40 \%$ respectively as shown in Fig. 4 a. These results are comparable to those of Zhang \& Liu, (2018) which also found that $95 \%$ of microplastics were $1-0.05 \mathrm{~mm}$ in size. The regression analysis of the number of microplastics retained on each sieve versus the sieve size showed a positive slope $\left(R^{2} \geq 0.9\right)$ Fig. 4 , denoting a significant increase in the number of small-sized microplastics in the irrigated farms. These results corroborate with those of other studies where inverse relationships have also been observed between the concentration of plastics particles and their sizes where samples were analyzed from soils (Klein et al., 2015).

\subsubsection{Total number of microplastics}


The microplastics in the irrigated farms ranged from $0.21-1.5$ items $\mathrm{g}^{-1}$. This is consistent with the results of Corradini et al., (2019), where the number of microplastics in soils from urban centers was 0.6$10.4 \mathrm{~g}^{-1}$. A high number of microplastics was found in irrigated farms adjacent to water sources and practicing irrigation throughout the year as shown in Fig. 5a. Farm 4 had the highest number of microplastics compared to other farms, probably because it was near to the intake and practiced irrigation throughout the year. In the conducted survey, farms 1, 4, and 7 (Fig. 5) were reported by farmers to be in flood-prone areas during heavy rains. This may have also contributed to the high number of microplastics established in these farms. Also, more microplastics were found on farm 1 compared to farm 2 situated beneath, probably because more plastics were deposited first in farm 1 since it receives water first, before reaching farm 2.

Compared to other irrigated farms, the number of microplastics in farm 10 was very low 67 items in total (Fig. 4b). Generally, the farm did not use River Themi's water for irrigation purposes and mainly relied on rainfall for its agricultural practices. The microplastics found on the farm are likely to be originating from atmospheric fallout, particles transported by wind, surface-runoffs during flooding, and perhaps from the sounding environment (Dris et al., 2016). The farm was an observation land in the present study to compare with those irrigated farms and the finding shows a significant difference from the comparison Fig. 4b.

\subsubsection{Quantity of macroplastics}

The collected macroplastics from farms ranged from $0.5-5.5 \mathrm{~kg}$ on a 50 by $30 \mathrm{~m}$ plot. The highest number of macroplastics (52 items) was established in farm 4 and the least (5 items) on the observational land; farm 10 . The weighed materials were variable, some may have gone unnoticed and blurred materials were not included. These high quantities of macroplastics might have been influenced by the time of sample collection which was out of farming season since most farms had not been cleared for planting and the position of the farm with regard to flooding. However, a direct comparison with other studies cannot be done because other studies have focused on different land characteristics, for instance, conventional agricultural land (Piehl et al., 2018). A relation of microplastics and macroplastics was generated to understand how proper farm management can lower the number of microplastics in irrigated farms and an exponential relationship was observed between the number of microplastics and the total number of items and the weight of materials as shown in Fig. 6.

\subsubsection{Type of plastics assessed}

a. Morphology of microplastics

Fibers were the most abundant type of plastics in the soil samples. Piehl et al.,(2018) and Zhang \& Liu, (2018) also established a high number of fibers in soil compartments. However, the total number of fiber in their studies cannot be related to the present one, since their works were on conventional agricultural land and soils from sludge application and wastewater irrigation field respectively. Fragments, films, and 
microbeads were observed in all the soil samples Fig. 4b where the microbeads from personal care and cosmetic products were the dominant types in the samples. Polypropylene (PP), Polystyrene (PS), and PET were the frequent polymers in all the farms. These results coincide with those of Rafique et al., (2020) which also established degraded pieces of PET bottles, PE bags, PS materials in soils. These similarities are likely due to the resemblances of the study areas.

b. Macroplastics

The dominant type of polymer across all farms was PET, this study established that $45-55,23-35,18-$ $25,12-21$, and $9-18 \%$ of all macroplastics in farms were PET, PS, Polyamide/nylon (PA), PP, high-density polyethylene (HDPE), and LDPE respectively. Between 4 and $9 \%$ of the macroplastics were Polymethyl methacrylate (PMMA), Polycarbonates, and Polyvinyl chloride (PVC) while Natural rubber, Acrylonitrile butadiene styrene (ABS) Polycarbonate (PC), Layered or multi-material mixed polymers, styreneacrylonitrile (SAN), Polyurethane were found in very small proportions $(<1 \%)$. Poly (ethylene: propylene:diene) copolymer (PE-PP), cellulose, and cellophane were also observed in some farms. Farmers affirmed that there was a great decrease in the deposition of LDPE in farms since its ban in June 2019. However, it will take a considerable time to eliminate them from the environment as they were frequently detected in the present study.

\subsection{Comparison of macro-and microplastics in rivers and irrigated farms}

\section{Type of polymer}

The type of macroplastics identified in rivers and irrigated farms showed no difference, since all locations were dominated by beverage bottles of water and soft drinks, shoes, and food wrapping materials. Though, In the riverbanks, other collected macroplastics were medical dispensing products such as syringes, medicine holders/ bottles, sanitary wear, hand-brushes, toothbrushes, toothpaste packages, detachment from car tires, clothes, food-packaging bottles, pieces of household appliances, personal care products, pens, and mattresses. Is relevant to say that the unique types of materials found in this riverbanks of Arusha city correspond with those established by Winton et al., (2020) where water bottles, food wrapping materials, and sanitary items dominated the rivers in UK, France, and Poland where used to define the policy for their regulation.

The total number of microplastics in the irrigation-dependent farms was higher than in the water columns and sediments. In addition, the number of microbeads in the irrigated farms was more than that in rivers. These results suggest that the irrigated farms in the present study, which were also located in the floodprone zones, are probably the sinks for most of the plastics transported by River Themi as Soils have been reported as potential sinks to retain and accumulate plastics (G. S. Zhang \& Liu, 2018; Nizzetto et al., 2016). 
In total,18 different type plastic polymers were identified from the sampled locations in the irrigated farms, sediments, and water columns. Amongst them the most frequently detected polymers with an overall detection frequency $>90 \%$ were PP, PET, and HDPE (Fig. 7b), This would be resulting of the high rate consumption of the materials among the people in Arusha area and also the poor management systems enacted in controlling the disposal of materials. Still, Similar results have been reported in previous studies where PE, PP, and PET were among the most commonly-occurring polymers in soils (Piehl et al., 2018 ; Zhang et al., 2020), water columns (Kataoka et al., 2019), and sediments (Jiang et al., 2019)

The ATR-FTIR results (Fig. 7a) obtained for the irrigated farms and rivers depicted similar trends in the spectrum, enabling a comparison in the type of polymers found in the study. A combination of the results from rivers and irrigated farms showed how river pollution contributes significantly to the deposition of plastics in irrigated farms. The results illustrate how irrigated farms receive plastic debris directly from urban rivers. Although farmers have adopted the technique of burning plastic debris brought in during flooding and irrigation to reduce their concentration, there are still large quantities retained on the farms which may affect the health of plants.

Studies on the effect of toxins from plastics on plants have been conducted. For instance, Galloway et al., (2017) showed that toxic substances can either be adsorbed onto surfaces or retained within the particle 'ecocorona' which can affect plant roots negatively. Also, additives contained in plastics may cause other toxicity on farms (Koelmans et al., 2019). Besides, based on the present survey, farmers whose farms experience flooding are exposed to an unconducive environment when clearing the deposited plastics brought; since the substances (some hazardous) stored in bottles are discharged in the farms. Also, the irrigated farms were affected by a new type of weed species (gugu karoti) which causes severe allergy to farmers and turning cows' milk to light-grey when the weed is consumed by cattle. Therefore, further studies are required to understand the extent of the effect of the weed on people, plants, and animals and their relationship with macroplastics and microplastics abundance in the area.

\section{Conclusions}

The present study investigated the relationship between macro-and microplastic pollution in the urban River Themi and their irrigation-dependent downstream smallholder farms. The quantity of microplastics in the irrigated farms was higher than in the water columns and river sediments. While the disparity in the number of microplastics enumerated from irrigation farms to rivers was to the power of 4 . These results suggest that irrigation-dependent farms are the sinks of macro-and microplastics from rivers passing through Arusha city in Tanzania. In addition, Irrigated farms receiving water throughout the year had a greater number of macro-and microplastics compared to those farms receiving intermittent water. The dominant type of macroplastics polymer in the irrigated farms and the riverbanks was PET, this comprehension of the levels of plastic pollution in agricultural areas is crucial for future enactment of management practices to protect flood-prone zones and farmlands from plastic pollution. Also, the present survey revealed that farmers whose farms are flood-prone were exposed to other problems related to the substances brought in within the plastics, heightening the dangers of farmers in the flood zones. 
This study is one of the few studies linking the microplastic pollutions of urban rivers to irrigationdependent farms in Sub-Saharan Africa and the findings clearly show that plastic pollution is not only a problem to the marine environments but also agricultural lands on the outskirts of urban centers. However, the study was limited by the fact that sampling was done only once during the dry season in November 2020. A longer period of study covering all the seasons can provide further insights into the seasonal variations of macroplastic deposition and microplastic concentration in the irrigation-dependent smallholder farms, water columns, and sediments. The values reported in this study might be mutable when sampling is done in another season due to hydrodynamic changes within the river. Also, further studies are required to understand the extent of the infections reported for the downstream irrigation farmers, plants, and animals from the chemicals and plastics deposited by floodwaters.

\section{Declarations}

Funding: Inter-University Council for East Africa (IUCEA) under world bank project sponsored my master's degree, buying of reagents, and paying off the field assistance and Water Infrastructure and Sustainable Energy (WISE)-Futures provided a car during the field work and paid for analysis cost.

Conflicts of interest/Competing interests: The authors declare that they have no known competing financial interests or personal relationships that could have appeared to influence the work reported in this paper

Availability of data and material: The data and materials are available upon requisition

Code availability: Not applicable

Authors' contributions: Mercy Kundu;-(Conceptualization, Methodology, software, Validation, Investigation, Writing-Original Draft preparation), Hans Komakech:-(Conceptualization, Software, Resources, writing- Review \& Editing, Supervision), George Lugomela: (Writing-Review \&Editing, Supervision),

\section{Acknowledgments}

This work was supported by the Inter-University Council for East Africa (IUCEA) under the World Bank project and the WISE-Futures Center in Nelson Mandela African Institution of Science and Technology.

\section{References}

Angnunavuri, P. N., Attiogbe, F., Dansie, A., \& Mensah, B. (2020). Consideration of emerging environmental contaminants in africa: Review of occurrence, formation, fate, and toxicity of plastic particles. Scientific African, 9, e00546. https://doi.org/10.1016/j.sciaf.2020.e00546

Biginagwa, F. J., Mayoma, B. S., Shashoua, Y., Syberg, K., \& Khan, F. R. (2016). First evidence of microplastics in the African Great Lakes: Recovery from Lake Victoria Nile perch and Nile tilapia. Journal 
of Great Lakes Research, 42(1), 146-149. https://doi.org/10.1016/j.jglr.2015.10.012

Browne, M. A., Crump, P., Niven, S. J., Teuten, E., Tonkin, A., Galloway, T., \& Thompson, R. (2011). Accumulation of microplastic on shorelines woldwide: sources and sinks. Environmental Science \& Technology, 45(21), 9175-9179.

Chacha, N., Njau, K. N., Lugomela, G. V., \& Muzuka, A. N. N. (2018). Hydrogeochemical characteristics and spatial distribution of groundwater quality in Arusha well fields, Northern Tanzania. Applied Water Science, 8(4), 1-23. https://doi.org/10.1007/s13201-018-0760-4

Chen, H., Jia, Q., Zhao, X., Li, L., Nie, Y., Liu, H., \& Ye, J. (2020). The occurrence of microplastics in water bodies in urban agglomerations: Impacts of drainage system overflow in wet weather, catchment landuses, and environmental management practices. Water Research, 183(August), 116073. https://doi.org/10.1016/j.watres.2020.116073

Corradini, F., Meza, P., Eguiluz, R., Casado, F., Huerta-Lwanga, E., \& Geissen, V. (2019). Evidence of microplastic accumulation in agricultural soils from sewage sludge disposal. Science of the Total Environment. https://doi.org/10.1016/j.scitotenv.2019.03.368

Dai, Z., Zhang, H., Zhou, Q., Tian, Y., Chen, T., Tu, C., Fu, C., \& Luo, Y. (2018). Occurrence of microplastics in the water column and sediment in an inland sea affected by intensive anthropogenic activities. Environmental Pollution, 242, 1557-1565.

de Souza Machado, A. A., Kloas, W., Zarfl, C., Hempel, S., \& Rillig, M. C. (2018). Microplastics as an emerging threat to terrestrial ecosystems. Global Change Biology, 24(4), 1405-1416.

Dobriyal, P., Badola, R., Tuboi, C., \& Hussain, S. A. (2017). A review of methods for monitoring streamflow for sustainable water resource management. Applied Water Science, 7(6), 2617-2628.

Dris, R., Gasperi, J., Rocher, V., Saad, M., Renault, N., \& Tassin, B. (2015). Microplastic contamination in an urban area: A case study in Greater Paris. Environmental Chemistry, 12(5), 592-599. https://doi.org/10.1071/EN14167

Dris, R., Gasperi, J., Saad, M., Mirande, C., \& Tassin, B. (2016). Synthetic fibers in atmospheric fallout: a source of microplastics in the environment? Marine Pollution Bulletin, 104(1-2), 290-293.

Frias, J., Pagter, E., Nash, R., O'Connor, I., Carretero, O., Filgueiras, A., Viñas, L., Gago, J., Antunes, J., Bessa, F., Sobral, P., Goruppi, A., Tirelli, V., Pedrotti, M. L., Suaria, G., Aliani, S., Lopes, C., Raimundo, J., Caetano, M., ... Gerdts, G. (2018). Standardised protocol for monitoring microplastics in sediments. JPI-Oceans BASEMAN Project, May, 33.

Galloway, T. S., Cole, M., \& Lewis, C. (2017). Interactions of microplastic debris throughout the marine ecosystem. Nature Ecology \& Evolution, 1(5), 1-8. 
Horton, A. A., \& Dixon, S. J. (2018). Microplastics: An introduction to environmental transport processes. Wiley Interdisciplinary Reviews: Water, 5(2), e1268.

Horton, A. A., Walton, A., Spurgeon, D. J., Lahive, E., \& Svendsen, C. (2017). Microplastics in freshwater and terrestrial environments: Evaluating the current understanding to identify the knowledge gaps and future research priorities. In Science of the Total Environment.

https://doi.org/10.1016/j.scitotenv.2017.01.190

Jiang, C., Yin, L., Li, Z., Wen, X., Luo, X., Hu, S., Yang, H., Long, Y., Deng, B., Huang, L., \& Liu, Y. (2019). Microplastic pollution in the rivers of the Tibet Plateau. Environmental Pollution, 249, 91-98. https://doi.org/10.1016/j.envpol.2019.03.022

Kataoka, T., Nihei, Y., Kudou, K., \& Hinata, H. (2019). Assessment of the sources and inflow processes of microplastics in the river environments of Japan. Environmental Pollution, 244, 958-965. https://doi.org/10.1016/j.envpol.2018.10.111

Kijazi, A. L., \& Reason, C. J. C. (2009). Analysis of the 1998 to 2005 drought over the northeastern highlands of Tanzania. Climate Research. https://doi.org/10.3354/cr00784

Klein, S., Worch, E., \& Knepper, T. P. (2015). Occurrence and spatial distribution of microplastics in river shore sediments of the Rhine-Main area in Germany. Environmental Science \& Technology, 49(10), 60706076.

Koelmans, B., Pahl, S., Backhaus, T., Bessa, F., van Calster, G., Contzen, N., Cronin, R., Galloway, T., Hart, A., \& Henderson, L. (2019). A scientific perspective on microplastics in nature and society. SAPEA.

Komakech, H. C., \& de Bont, C. (2018). Differentiated access: Challenges of equitable and sustainable groundwater exploitation in Tanzania. Water Alternatives.

Lagarde, F., Olivier, O., Zanella, M., Daniel, P., Hiard, S., \& Caruso, A. (2016). Microplastic interactions with freshwater microalgae: hetero-aggregation and changes in plastic density appear strongly dependent on polymer type. Environmental Pollution, 215, 331-339.

Lahens, L., Strady, E., Kieu-Le, T. C., Dris, R., Boukerma, K., Rinnert, E., Gasperi, J., \& Tassin, B. (2018). Macroplastic and microplastic contamination assessment of a tropical river (Saigon River, Vietnam) transversed by a developing megacity. Environmental Pollution, 236, 661-671.

https://doi.org/10.1016/j.envpol.2018.02.005

Liro, M., van Emmerik, T., Wyzga, B., Liro, J., \& Mikuś, P. (2020). Macroplastic storage and remobilization in rivers. Water (Switzerland), 12(7), 22-29. https://doi.org/10.3390/w12072055

Mani, T., Hauk, A., Walter, U., \& Burkhardt-Holm, P. (2015). Microplastics profile along the Rhine River. Scientific Reports, 5(1), 17988. https://doi.org/10.1038/srep17988 
Masura, J., Baker, J., Foster, G., \& Arthur, C. (2015). Laboratory Methods for the Analysis of Microplastics in the Marine Environment. NOAA Marine Debris Program National, July, 1-39.

https://marinedebris.noaa.gov/sites/default/files/publications-

files/noaa_microplastics_methods_manual.pdf

McCormick, A. R., Hoellein, T. J., London, M. G., Hittie, J., Scott, J. W., \& Kelly, J. J. (2016). Microplastic in surface waters of urban rivers: concentration, sources, and associated bacterial assemblages. Ecosphere, 7(11), e01556.

Mehdinia, A., Dehbandi, R., Hamzehpour, A., \& Rahnama, R. (2020). Identification of microplastics in the sediments of southern coasts of the Caspian Sea, north of Iran. Environmental Pollution, 258, 113738. https://doi.org/10.1016/j.envpol.2019.113738

Merga, L. B., Redondo-Hasselerharm, P. E., Van den Brink, P. J., \& Koelmans, A. A. (2020). Distribution of microplastic and small macroplastic particles across four fish species and sediment in an African lake. Science of the Total Environment, 741, 140527. https://doi.org/10.1016/j.scitotenv.2020.140527

Mintenig, S. M., Kooi, M., Erich, M. W., Primpke, S., Redondo- Hasselerharm, P. E., Dekker, S. C., Koelmans, A. A., \& van Wezel, A. P. (2020). A systems approach to understand microplastic occurrence and variability in Dutch riverine surface waters. Water Research, 176, 115723.

https://doi.org/10.1016/j.watres.2020.115723

Mohamed, M. A., Jaafar, J., Ismail, A. F., Othman, M. H. D., \& Rahman, M. A. (2017). Fourier transform infrared (FTIR) spectroscopy. In Membrane Characterization (pp. 3-29). Elsevier.

Nanyaro, J. T., Aswathanarayana, U., Mungure, J. S., \& Lahermo, P. W. (1984). A geochemical model for the abnormal fluoride concentrations in waters in parts of northern Tanzania. Journal of African Earth Sciences. https://doi.org/10.1016/s0731-7247(84)80007-5

Nizzetto, L., Langaas, S., \& Futter, M. (2016). Pollution: do microplastics spill on to farm soils? Nature, $537(7621), 488$.

Piehl, S., Leibner, A., Löder, M. G. J., Dris, R., Bogner, C., \& Laforsch, C. (2018). Identification and quantification of macro- and microplastics on an agricultural farmland. Scientific Reports, 8(1), 1-9. https://doi.org/10.1038/s41598-018-36172-y

Rafique, A., Irfan, M., Mumtaz, M., \& Qadir, A. (2020). Spatial distribution of microplastics in soil with context to human activities: a case study from the urban center. Environmental Monitoring and Assessment, 192(11). https://doi.org/10.1007/s10661-020-08641-3

Rillig, M. C., Ziersch, L., \& Hempel, S. (2017). Microplastic transport in soil by earthworms. Scientific Reports, 7(1), 1-6. 
Thomas, D., Schütze, B., Heinze, W. M., \& Steinmetz, Z. (2020). Sample preparation techniques for the analysis of microplastics in soil-a review. Sustainability (Switzerland), 12(21), 1-28.

https://doi.org/10.3390/su12219074

Thompson, R. C., Moore, C. J., Vom Saal, F. S., \& Swan, S. H. (2009). Plastics, the environment and human health: current consensus and future trends. Philosophical Transactions of the Royal Society B: Biological Sciences, 364(1526), 2153-2166.

van Emmerik, T., Strady, E., Kieu-Le, T.-C., Nguyen, L., \& Gratiot, N. (2019). Seasonality of riverine macroplastic transport. Scientific Reports, 9(1), 13549. https://doi.org/10.1038/s41598-019-50096-1

Winton, D. J., Anderson, L. G., Rocliffe, S., \& Loiselle, S. (2020). Macroplastic pollution in freshwater environments: Focusing public and policy action. Science of the Total Environment, 704, 135242. https://doi.org/10.1016/j.scitotenv.2019.135242

Zhang, D., Cui, Y., Zhou, H., Jin, C., Yu, X., Xu, Y., Li, Y., \& Zhang, C. (2020). Microplastic pollution in water, sediment, and fish from artificial reefs around the Ma'an Archipelago, Shengsi, China. Science of the Total Environment, 703, 134768. https://doi.org/10.1016/j.scitotenv.2019.134768

Zhang, G. S., \& Liu, Y. F. (2018a). The distribution of microplastics in soil aggregate fractions in southwestern China. Science of the Total Environment, 642, 12-20.

https://doi.org/10.1016/j.scitotenv.2018.06.004

Zhang, G. S., \& Liu, Y. F. (2018b). The distribution of microplastics in soil aggregate fractions in southwestern China. Science of the Total Environment, 642, 12-20.

https://earthexplorer.usgs.gov/

https://simple-plastics.eu/index.html

\section{Figures}




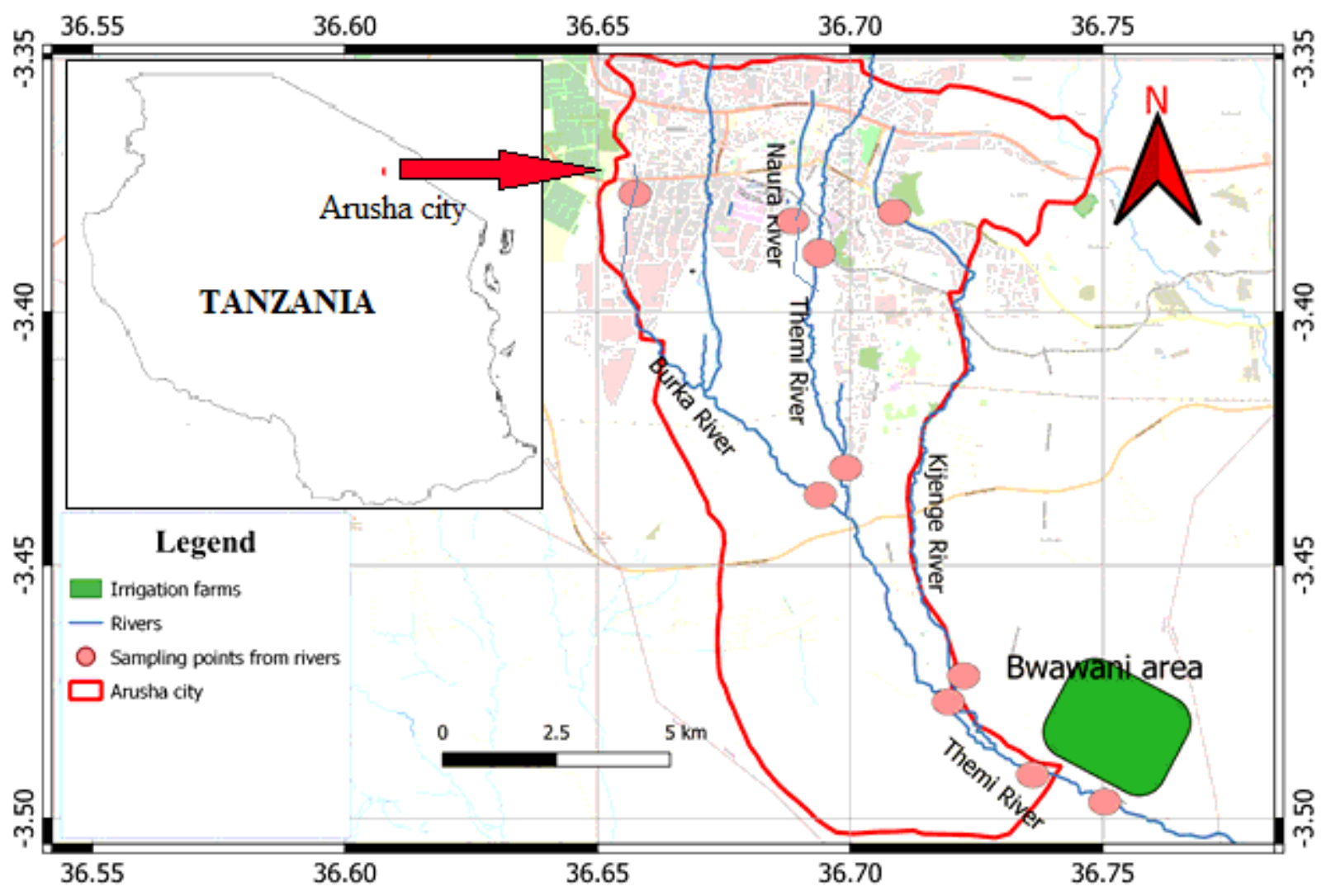

Figure 1

Map of the sampled locations on River Themi, its tributaries and Bwawani area. Note: The designations employed and the presentation of the material on this map do not imply the expression of any opinion whatsoever on the part of Research Square concerning the legal status of any country, territory, city or area o bbnhjr of its authorities, or concerning the delimitation of its frontiers or boundaries. This map has been provided by the authors. 

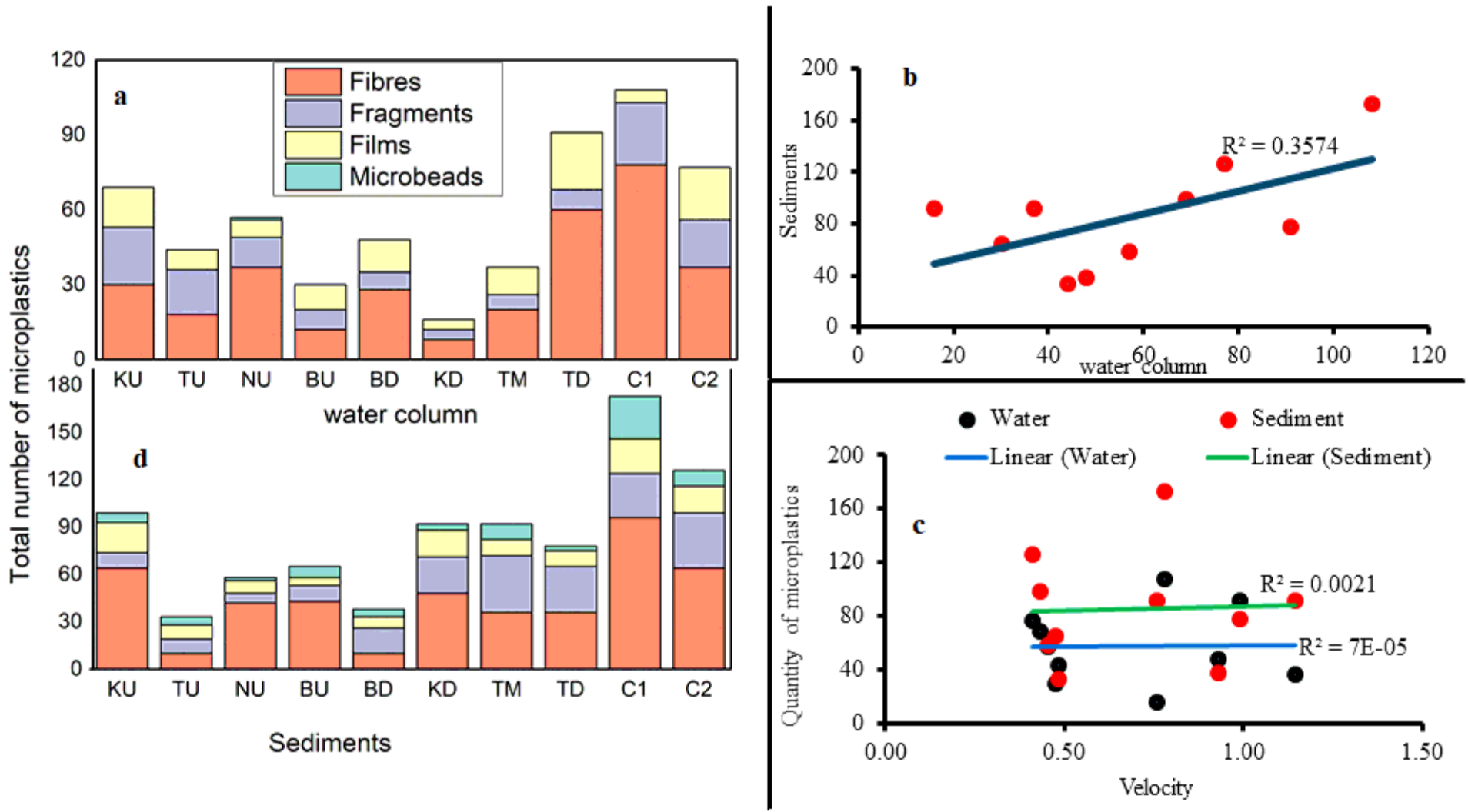

Figure 2

Distribution of microplastics in the water column and sediment and relationships (The sampling station for rivers $\mathrm{KU}=$ Kijenge upstream, $\mathrm{TU}=$ Themi Upstream, NU = Naura upstream, BU = Burka Upstream, BD = Burka downstream, $\mathrm{KD}$ Kijenge downstream, $\mathrm{TM}=$ Themi midstream, $\mathrm{TD}=$ Themi downstream, $\mathrm{C1}$ = Canal 1 and $\mathrm{C} 2=$ canal 2 )
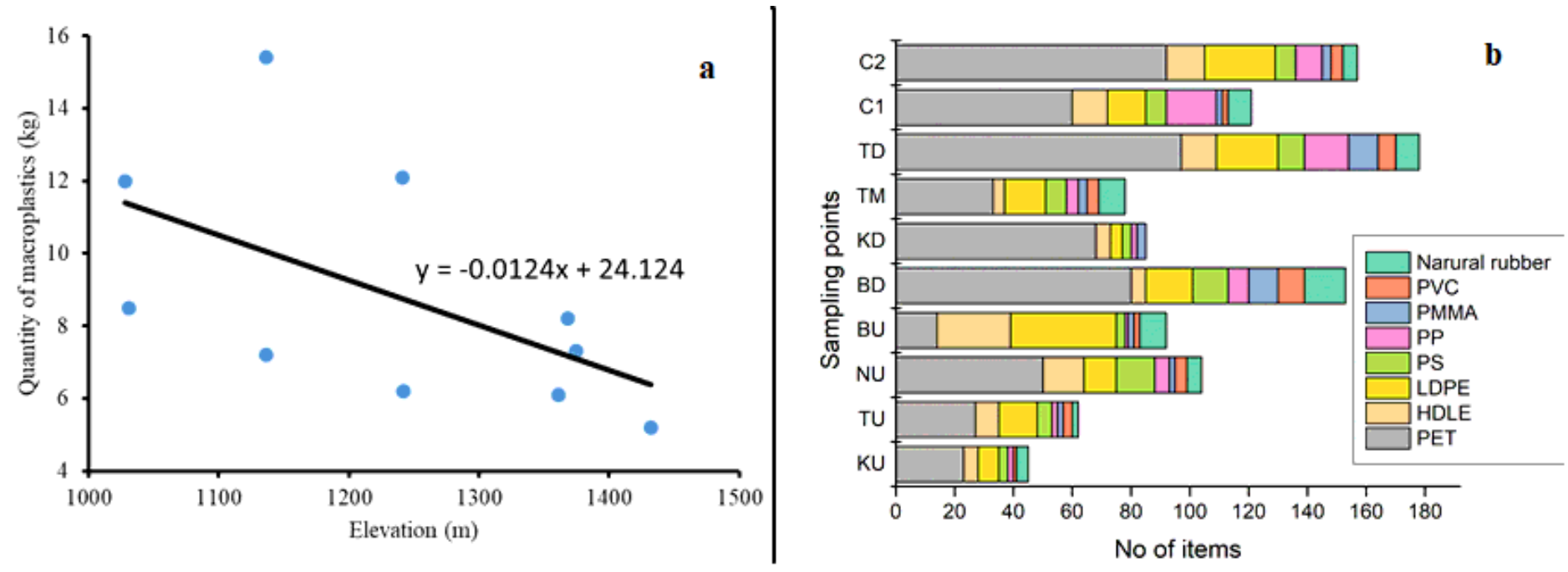

Figure 3 
The relationship between quantity of macroplastics and elevation (a),and types of polymers identified from the collected items macroplastics (b).
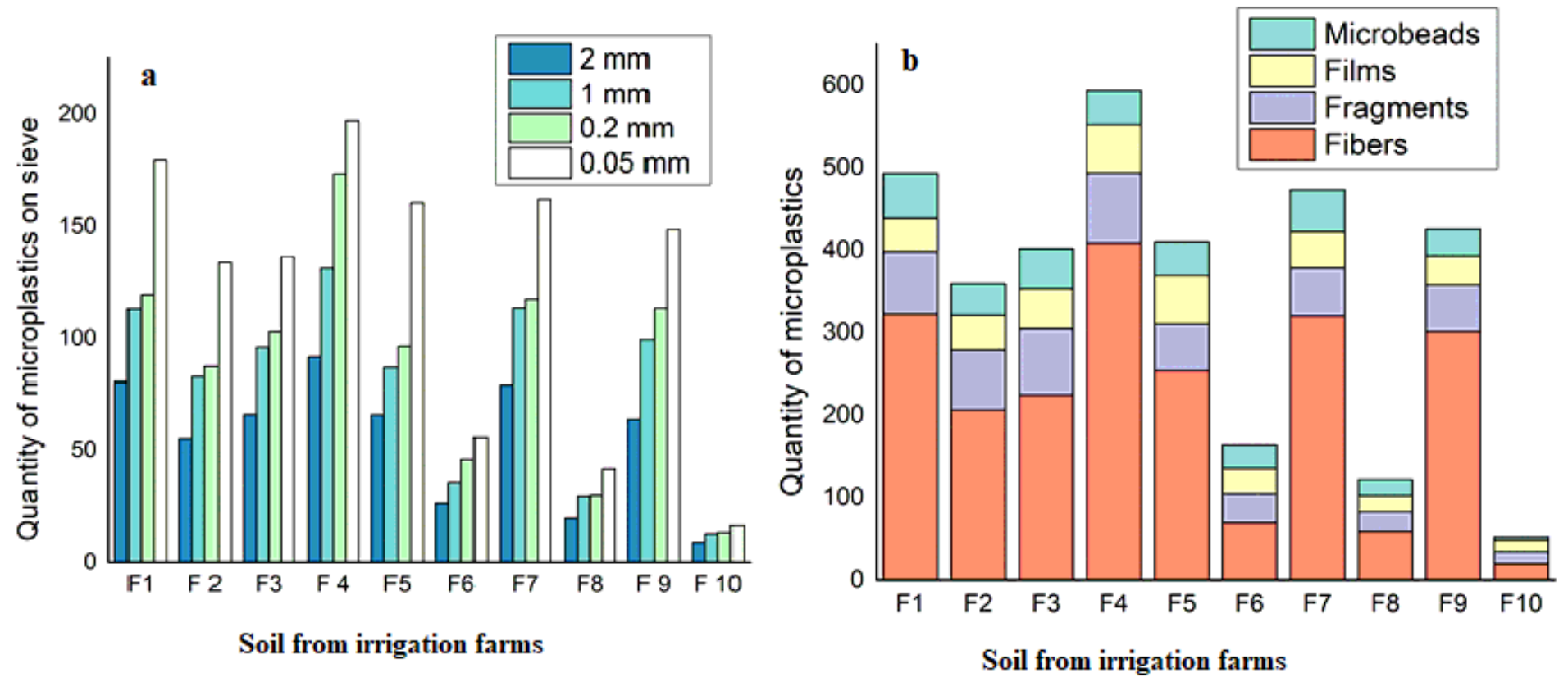

Figure 4

Quantity of microplastics enumerated from irrigation farms (a shows the total number of microplastics retained on each sieve from $500 \mathrm{~g}$ of soil and $\mathrm{b}$ the total average of microplastics from $500 \mathrm{~g}$ of soil) 


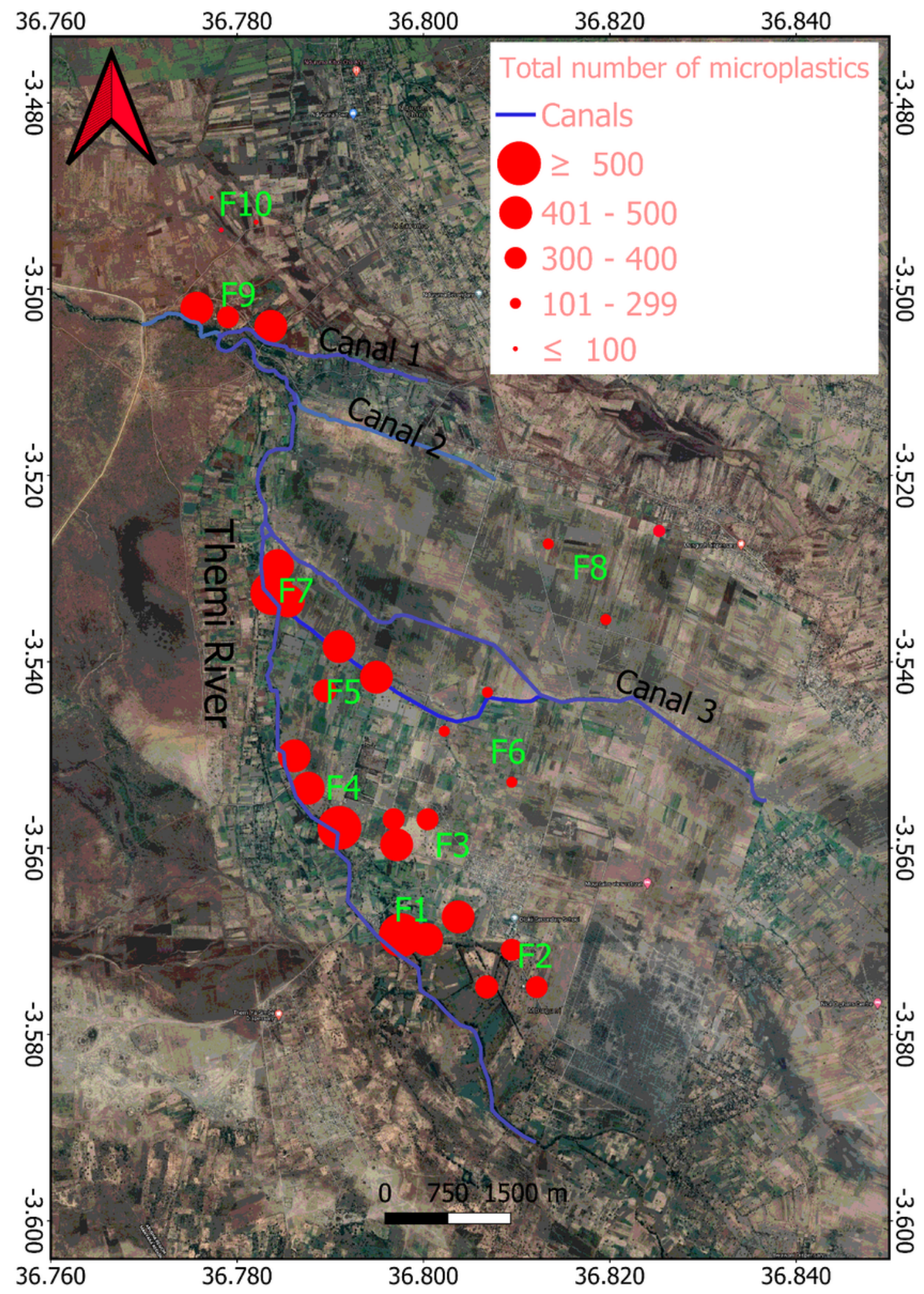

Figure 5

Spatial distribution of microplastics in soils of irrigated farms and non-irrigated farm 


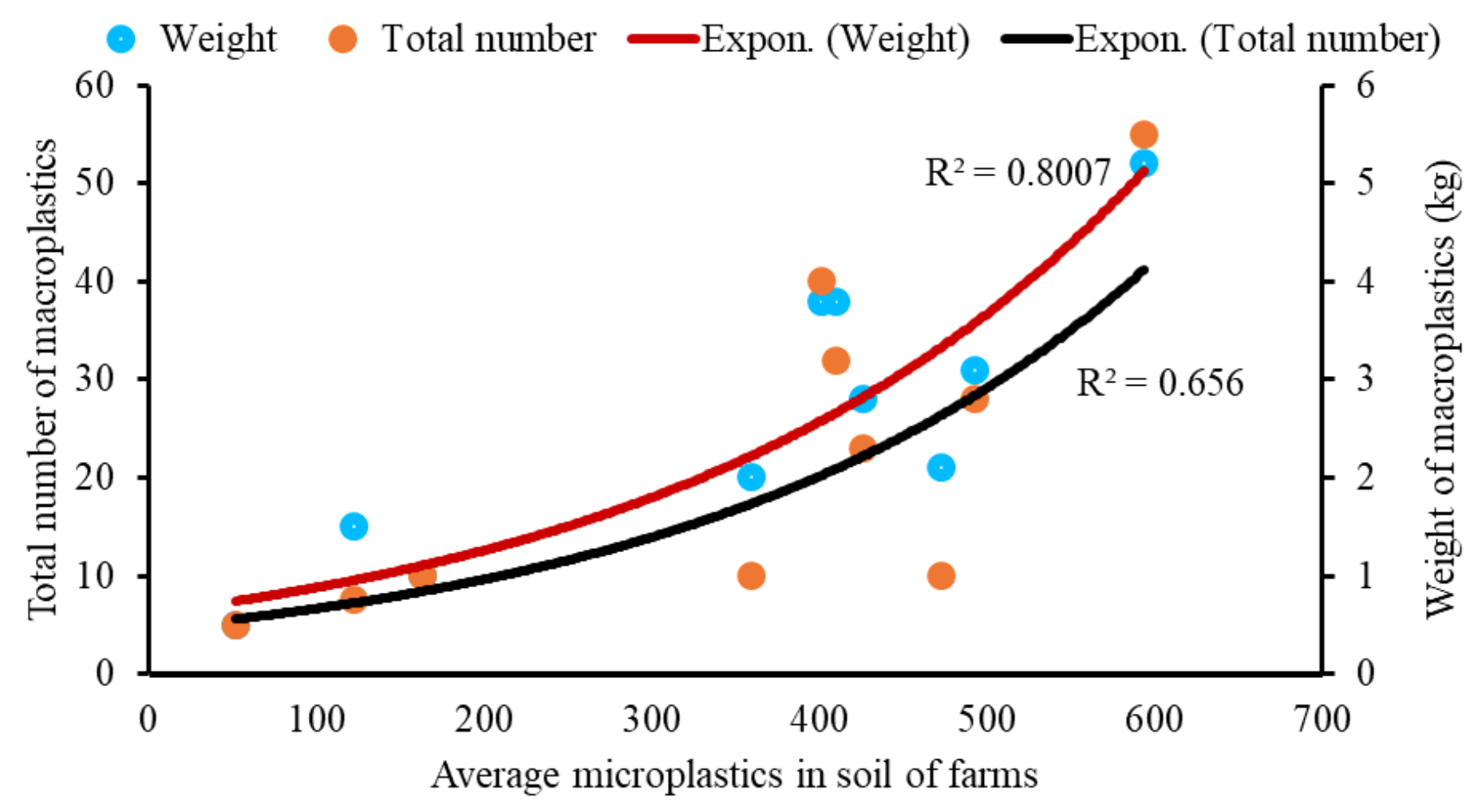

Figure 6

Relationship between the weight of macroplastics and the total number of microplastics in irrigated farms (the items are those particles counted from the measured materials)
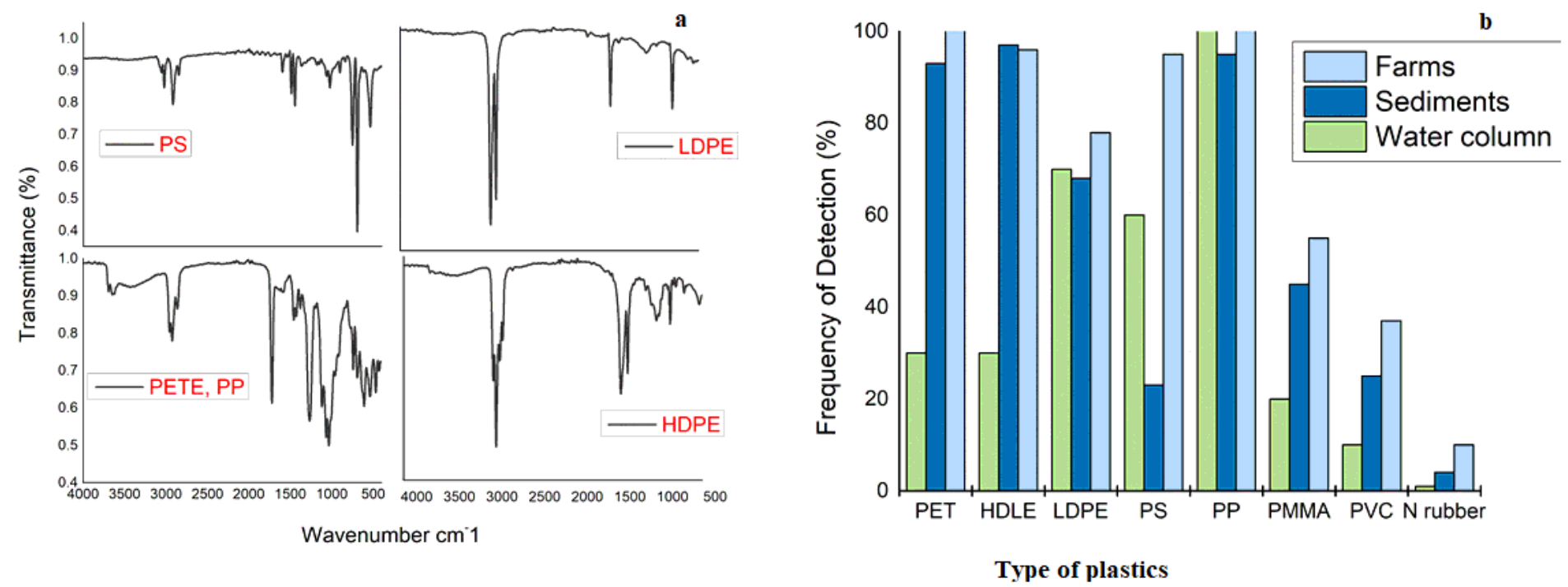

Figure 7

Type (a) and detection frequency (b) of polymers identified for plastics 